\title{
Cone-beam computed tomography study of the root and canal morphology of mandibular permanent anterior teeth in a Chongqing population
}

\author{
This article was published in the following Dove Press journal: \\ Therapeutics and Clinical Risk Management \\ 23 December 2015 \\ Number of times this article has been viewed
}

\author{
Yang Zhengyan \\ Lu Keke \\ Wang Fei \\ Li Yueheng \\ Zhou Zhi
}

Department of Preventive Dentistry, The College of Stomatology, The Affiliated Hospital of Stomatology, Chongqing Medical University,

Chongqing, People's Republic of China

Correspondence: Zhou Zhi Department of Preventive Dentistry, The College of Stomatology, Chongqing Medical University, 426\# Songshibei Road, Chongqing 40I I47, People's Republic of China Email zhouzhi_050918@hotmail.com
Objective: To investigate the root and canal morphology of permanent mandibular anterior teeth in a Chongqing population using cone-beam computed tomography (CBCT).

Methods: CBCT images of 1,725 patients in a Chongqing population were selected, and a total of 9,646 mandibular anterior teeth were analyzed. The number of root canals and the canal configurations were investigated.

Results: In total, $0.3 \%(11 / 3,257)$ of lateral incisors and $0.8 \%(26 / 3,014)$ of canines had double roots, and $3.8 \%(127 / 3,375)$ of central incisors, $10.6 \%(345 / 3,257)$ of lateral incisors, and $4.2 \%$ $(127 / 3,014)$ of canines had multi-root canals. The difference in the incidence of multi-canals in lateral incisors between female and male was statistically significant. The frequency of multicanals in the different age groups was 5.0\% for central incisors for ages $21-30$ years, $14.7 \%$ for lateral incisors for ages $41-50$ years, and $8.1 \%$ for canines for ages $41-50$ years.

Conclusion: With the limitations of the current study, we found that a high percentage of mandibular anterior teeth had multiple canals in the studied Chinese Chongqing population. The current data may provide clinicians practicing in Chongqing with a more thorough understanding of root canal morphology.

Keywords: cone-beam computed tomography, mandibular anterior teeth, root canal morphology, radicular grooves

\section{Introduction}

A comprehensive understanding of the complexity of the root canal system is necessary for successful endodontic treatment. Furthermore, knowledge of the internal anatomy of the teeth is fundamental for the proper cleaning and filling of the root canal system and the consequent success of endodontic treatment. ${ }^{1,2}$ The clinician should be familiar with the most common types of dental anatomy and the most common anatomic variations encountered in daily practice. ${ }^{1}$ Mandibular anterior teeth typically present with a single root and a single canal. However, canal configurations in mandibular anterior teeth may significantly vary with respect to ethnicity, race, and sex. In particular, a mandibular anterior tooth may have additional canals and a variety of canal configurations. ${ }^{3}$

A number of techniques have been used to study the morphologic characteristics of the root canal system. Conventional methods such as cross-sectioning, root canal staining and root clearing, scanning electron microscopy, and stereomicroscopy are destructive techniques when used to identify the configuration of canals. Radiography is one of the most important clinical tools in endodontic therapy; this approach is used in the determination of the root canal configuration, in making a diagnosis and in periodic 
follow-up examinations. However, traditional radiographic images compress the three-dimensional (3D) anatomy into a two-dimensional image, and this compression results in some important information about the tooth and its surrounding tissues being visualized only in the mesio-distal plane. Cone-beam computed tomography (CBCT) provides a noninvasive technique for more precise investigation of the root canal system and facilitates a detailed investigation of both the external and the internal anatomy of the tooth. This anatomy can be simultaneously or separately observed from different angles by reconstructing the 3D images, and the characteristics of the tooth can be both qualitatively and quantitatively assessed. The major advantages of CBCT include the substantial reduction in radiation exposure and the higher quality image rendering for the assessment of dental hard tissues. As a result, this non-invasive, 3D imaging technique has many endodontic applications, especially with respect to the improvement of diagnostic quality and automated image analysis. ${ }^{4}$

Many scholars have performed clinical analyses to investigate the root canal configuration and the morphology of the anterior roots using different techniques, and different numbers of root canals in these teeth have been found. Higher incidences of multi-canals in mandibular anterior teeth roots have been reported in Chinese populations. ${ }^{5-8}$ However, most investigations have been performed on extracted teeth, and few studies have focused on the in vivo radiographic process using digital systems. Therefore, the purpose of this study was to report the clinical incidence of the root number and canal morphology of mandibular anterior teeth in a Chongqing population using CBCT.

\section{Materials and methods}

All experimental procedures in this study were approved by the ethics committee of the Stomatology Hospital Affiliated to Chongqing Medical University.

CBCT radiographs from a Chongqing population obtained during the period from January 1, 2013 to June 30, 2013 were collected and studied at the Department of Radiology in the Affiliated Hospital of Stomatology at Chongqing Medical University in Chongqing, People's Republic of China. The CBCT images were taken at $120 \mathrm{kv}$ and $5 \mathrm{~mA}$, with a scan time of 9-18 seconds by skilled radiologists according to the manufacturer's instructions. The voxel size was $0.125 \mathrm{~mm}$ and the slice thickness was $1.0 \mathrm{~mm}$.

\section{Inclusion criteria of CBCT images}

The inclusion criteria were as follows: i) untreated permanent mandibular anterior teeth; ii) no deep dental caries or lesions, root fillings, or fiber postrestorations; iii) fully developed roots and canals without resorption or calcification; and iv) CBCT images of good quality within the permanent mandibular anterior region. For the sample size calculation, we adopted a standard error of $5 \%$, a confidence interval level of $95 \%$, and the multi-canal morbidity of mandibular anterior teeth with a previous prevalence of $2.98 \%-67.5 \%$ (Table 1 ). The minimum number of samples was estimated to be $222 .{ }^{9}$

\section{Classification of canal configuration}

The canal configuration of each tooth was recorded according to the method of Vertucci (Figure 1), ${ }^{1}$ and two additional types were added: type IX (two roots, with one root canal each located in the buccal and lingual or mesial and distal areas) and type $\mathrm{X}$ (with one canal located in the mesial area and one located in the distal area).

\section{Analysis of CBCT digital images}

All CBCT digital images were read by a researcher using a desktop computer (Samsung, Chesapeake, VA, USA), and I-CAT software (Imaging Sciences International, LLC, Hatfield, PA, USA) was used to analyze mandibular anterior teeth in the axial, sagittal, and coronal planes. The contrast and brightness of the images were adjusted to ensure optimal visualization with the software. The following data were observed and recorded: i) the morphology and number of roots and ii) the number of canals per root and canal configuration. The patients were divided into six groups (younger than 20 years, 21-30 years, $31-40$ years, $41-50$ years, $51-60$ years, and above 60 years of age). The sex (female or male) of the patients and the location of the included teeth were also recorded.

\section{The standard consistency test (kappa value)}

To ensure the reliability of the research results, 50 cases of CBCT were drawn at random, and the investigator read the 50 CBCT images according to the criteria of two readings at different times of the day initially, and again with a 1-week interval between readings. A standard consistency check (kappa value) of the results was performed at two different times.

When the kappa value was $\leq 0.4$, the reliability was considered unqualified; when the kappa value was between 0.41 and 0.6 , the reliability was considered moderate; when the kappa value was between 0.61 and 0.8 , the reliability was considered excellent; and when the kappa value was between 0.81 and 1.0 , the reliability was considered completely reliable. ${ }^{10}$

\section{Statistical analysis}

Data were analyzed with the chi-square test and one-way analysis of variance (ANOVA) (SPSS 17.0). The significance level was set at 0.05 . 


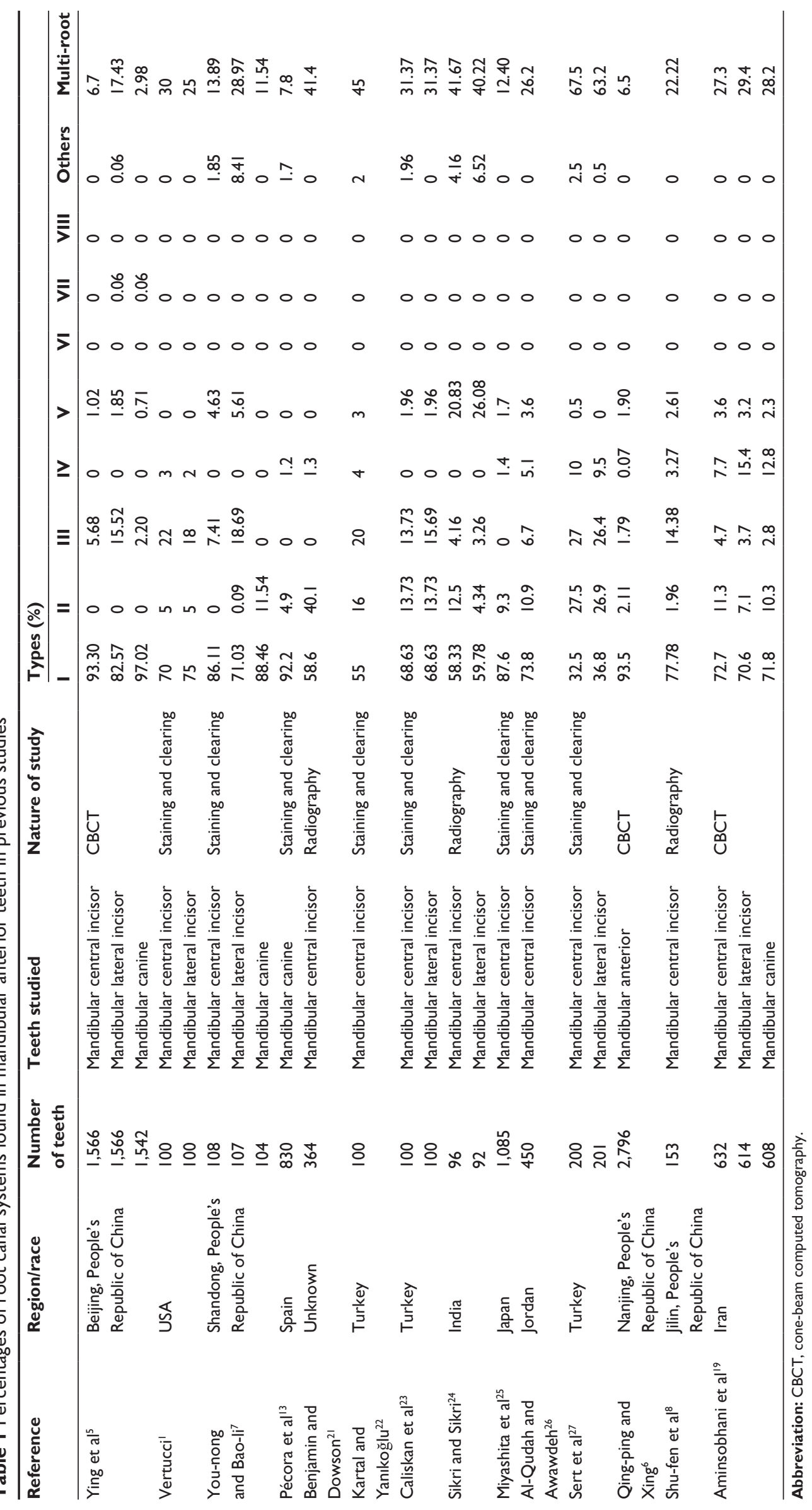




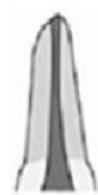

Type I

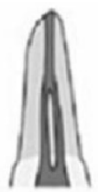

Type II

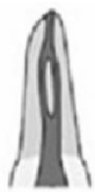

Type III

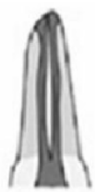

Type IV

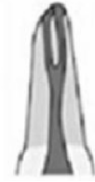

Type V

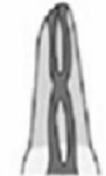

Type VI

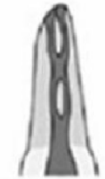

Type VII Type VIII

Figure I Illustration of the variations in permanent mandibular anterior teeth according to the Vertucci method.

\section{Results}

The result of the consistency check of the readings by the examiners was 0.819 , indicating that the clinical information was completely reliable in this study.

CBCT images of 9,646 permanent mandibular anterior teeth from 1,725 patients (males: 923, females: 802) in a Chongqing population were used in this study.

\section{Root morphology}

All of the mandibular central incisors had a single root, $0.3 \%$ of the mandibular lateral incisors and $0.8 \%$ of mandibular canines had two roots, and all of the root furcations of these teeth were located between the middle $1 / 3$ and the apical $1 / 3$ of the root.

\section{Root canal pattern}

The results for the analyses of root canal morphology and the number of root canals according to Vertucci's root canal morphology classification for the 9,646 mandibular anterior teeth are shown in Table 2 and Figure 2.

The majority of permanent mandibular anterior teeth had a type I root canal morphology; the second most common finding was type III. The prevalence of multi-canals in the mandibular anterior teeth was as follows: central incisors, $3.8 \%(127 / 3,375)$; lateral incisors, $10.6 \%(345 / 3,257)$; and canines, $4.2 \%(127 / 3,014)$ (Table 2).

In this study, no significant difference was found in the prevalence of multi-root canals between the left and right sides of the mouth. Regarding sex, $9.4 \%$ of the mandibular lateral incisors in males had a second canal, whereas this value was $11.9 \%$ in females; this result revealed a significant difference between sex $(P<0.05)$. The other findings showed no significant differences.

This study also examined the distribution of multiple root canals of the mandibular anterior teeth at different ages. There were six age groups included in this study, and their multiroot incidence rates were $4.9 \%$ (younger than 20 years), $6.0 \%$ ( $21-30$ years), $7.4 \%$ ( $31-40$ years), $9.1 \%$ ( $41-50$ years), $5.2 \%$ (51-60 years), and 2.6\% (above 60 years). Therefore, the highest incidence of multiple root canals in mandibular anterior teeth was $9.1 \%$ in the $41-50$ years age group. This prevalence increased with age, but after 41-50 years of age, the incidence rate decreased.

\section{Discussion}

There are a variety of methods used in the morphologic evaluation of the roots of teeth and the root canal system, including decalcification, ${ }^{11}$ dye injection, ${ }^{12}$ ex vivo radiography, ${ }^{3}$ in vitro macroscopic examination, ${ }^{13}$ scanning electron microscopic examination of the pulpal floor, and grinding or sectioning. ${ }^{3}$ However, these methods for identifying the configuration of canals constitute destructive techniques.

Conventional periapical radiographs are valuable diagnostic tools for assessing root canal morphology in vivo. Nevertheless, these radiographs are not reliable because of inherent limitations, such as the distortion and superimposition of bony and dental structures. ${ }^{4}$

Table 2 Incidence of different root canal morphologies of permanent mandibular anterior teeth (teeth [proportion \%])

\begin{tabular}{|c|c|c|c|c|c|c|c|c|}
\hline Tooth & Type I & Type II & Type III & Type IV & Type V & Type X & Type IX & $\begin{array}{l}\text { Type }(\mathrm{II}+\mathrm{III}+\mathrm{IV}+ \\
\mathbf{V}+\mathbf{X}+\mathrm{IX})\end{array}$ \\
\hline 33 & I,452 (96.4\%) & II (0.7\%) & $26(1.7 \%)$ & $0(0 \%)$ & $6(0.4 \%)$ & $0(0 \%)$ & $12(0.8 \%)$ & 55 (3.6\%) \\
\hline 43 & I,435 (95.2\%) & II (0.7\%) & 37 (2.5\%) & $4(0.3 \%)$ & $6(0.4 \%)$ & $0(0 \%)$ & 14 (0.9\%) & 72 (4.8\%) \\
\hline 32 & I,457 (89.8\%) & $18(1.1 \%)$ & 122 (7.5\%) & $5(0.3 \%)$ & $16(1.0 \%)$ & $0(0 \%)$ & $4(0.2 \%)$ & 165 (10.2\%) \\
\hline 42 & I,455 (89.0\%) & 17 (1.0\%) & 129 (7.9\%) & $5(0.3 \%)$ & $22(1.3 \%)$ & $0(0 \%)$ & $7(0.4 \%)$ & $180(11.0 \%)$ \\
\hline 31 & I,624 (96.4\%) & $4(0.2 \%)$ & $43(2.6 \%)$ & $2(0.1 \%)$ & $12(0.7 \%)$ & $0(0 \%)$ & $0(0 \%)$ & 61 (3.6\%) \\
\hline 41 & I,624 (96.I\%) & I (0.I\%) & $48(2.8 \%)$ & $2(0.1 \%)$ & $14(0.8 \%)$ & I (0.1\%) & $0(0 \%)$ & 66 (3.9\%) \\
\hline Total & 9,047 (93.8\%) & $62(0.6 \%)$ & $405(4.2 \%)$ & $18(0.2 \%)$ & $76(0.8 \%)$ & I (0.0\%) & $37(0.4 \%)$ & $599(6.2 \%)$ \\
\hline
\end{tabular}

Notes: 3I, left mandibular central incisor; 4I, right mandibular central incisor; 32, left mandibular lateral incisor; 42, right mandibular lateral incisor; 33, left mandibular canine; 43 , right mandibular canine. 


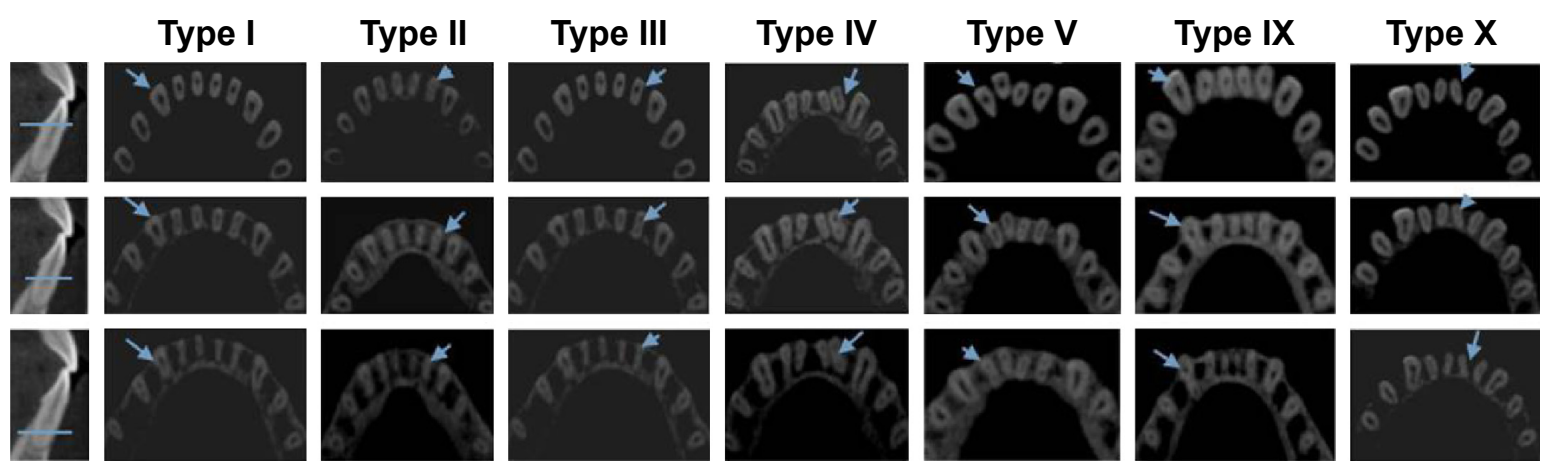

Figure 2 CBCT images showing the various canal morphologies in permanent mandibular anterior teeth.

Notes: The blue arrows indicate the root canal morphology of each section of the root. All CBCT images of the roots were simultaneously sectioned horizontally in the apical, middle, and cervical thirds. The horizontal line indicates the plane of different sections.

Abbreviation: $\mathrm{CBCT}$, cone-beam computed tomography.

CBCT is widely used in implantology and maxillofacial reconstruction; this approach is also used in endodontic diagnosis in cases requiring surgical endodontics and for evaluating canal preparation, obturation, and root filling removal. A recent study reported that $\mathrm{CBCT}$ was as precise as the modified canal staining and tooth clearing method in determining root canal morphology. ${ }^{14}$ The main advantages of $\mathrm{CBCT}$ imaging are its nondestructive nature and that the $3 \mathrm{D}$ reconstruction and visualization include the external and internal anatomy of both the teeth and surrounding bony structures. ${ }^{15-18}$ The most notable advantages of CBCT are its high accuracy, its significantly lower effective radiation dose or short exposure time ( $2-5$ seconds), and its lower expense compared to conventional CT. In addition, $\mathrm{CBCT}$ measurements are geometrically accurate because the $\mathrm{CBCT}$ voxels (3D pixels containing data) are isotropic. ${ }^{17,18}$ In particular, $\mathrm{CBCT}$ is of great value for making a distinction between multi-root canals from radicular grooves (RGs).

Previous studies have reported a wide range of results for multi-canal detection $(2.98 \%-67.5 \%)$ of the mandibular anterior teeth (Table 1). The results of the current study showed that the incidence rates of multi-canals for the mandibular incisors, the mandibular lateral incisors, and the mandibular canines were in accordance with the results of Ying et $\mathrm{al}^{5}$ and Qingping and Xing ${ }^{6}$ but were different from those of Aminsobhani et al. ${ }^{19}$ These variations may be attributed to differences in sex, racial origin, genetic factors, and research methods.

The results of previous studies ${ }^{5-8,14,19-27}$ suggested that there was a lower prevalence of multi-root canals in mandibular canines than in central incisors and lateral incisors, and most of the studies provided evidence that the prevalence of multi-roots was higher in mandibular lateral incisors, which is consistent with our current study.

The results of this study demonstrated that mandibular lateral incisors had a much higher incidence of multi-root canals compared with the other mandibular anterior teeth. This difference compared to the results of previous studies may be due to variations in examination techniques, classification methods, sample size, and regional and ethnic distributions of teeth. ${ }^{27}$

This study also included a symmetry analysis and an agerelated and sex-specific correlation of multi-root canals. The incidence of a second canal in permanent mandibular incisors was relatively higher in males in the current study, which may provide useful information to endodontists during root canal therapy. However, there was no significant difference found between sex in terms of symmetry. This study also found that the rate of multi-root canals followed a trend with age and growth similar to Ying et al's studies, ${ }^{5}$ and this may be due to the generation of tertiary dentinogenesis. The results of this study also showed that RGs may have a relationship to age, but this mechanism is unclear.

With micro computed tomography (micro-CT) used widely in confirming multi-root canals, many studies have reported the incidence of multi-root canals in mandibular incisors. For instance, Milanezi de Almeida et $\mathrm{a}^{28}$ reported that 340 mandibular incisors with type I and III configurations represented $92 \%$ of the mandibular incisors; these results are similar to those in our study. The technique of micro-CT facilitates detailed investigation of both the external and the internal anatomy of the tooth, which can be observed simultaneously or separately from different angles by reconstructing the 3D images. However, micro-CT has been applied mainly to extracted human teeth studied in vitro, and most studies to date have been performed ex vivo.

When we studied the CBCT images, we noticed that multiple, complex canals in the mandibular anterior teeth included oval and flattened canals, and the mesial and distal surfaces often contained long depressions known as RGs. The depth of the RGs may be related to the variations in the mandibular anterior teeth root canal systems. Only a few 


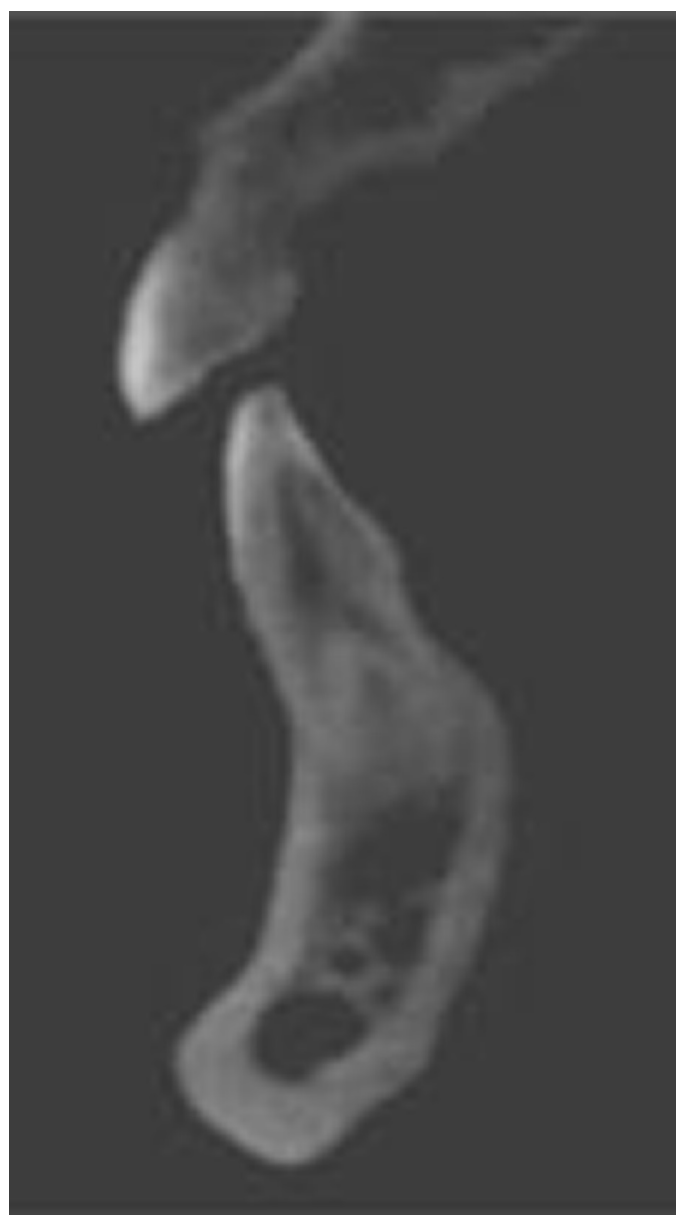

Figure $3 \mathrm{CBCT}$ images showing additional canal morphology (type IX) in permanent mandibular anterior teeth.

Abbreviation: $\mathrm{CBCT}$, cone-beam computed tomography.

studies have investigated RGs in the mandibular anterior teeth; therefore, analyses of the relationship between multiple canals and RGs may have important clinical significance.

Our study investigated different types of root canal morphology for the mandibular anterior teeth. We identified more types than those included in the Vertucci method, such as type IX (Figure 3). Our findings highlight the diversity and complexity of the root canal morphology of the mandibular anterior teeth. At the same time, these results also prompt the reclassification of multi-root canal morphology in the future.

\section{Conclusion}

$\mathrm{CBCT}$ is a useful tool in the clinical assessment of root canal morphology. Even with the limitations of the current study, we found that a high percentage of mandibular anterior teeth had multiple canals in the studied Chinese Chongqing population. The current data may provide clinicians practicing in Chongqing with a more thorough understanding of root canal morphology.

\section{Acknowledgment}

The authors received no financial support with respect to the authorship and/or publication of this article.

\section{Disclosure}

The authors report no conflicts of interest in this work.

\section{References}

1. Vertucci FJ. Root canal morphology \& its relationship to endodontic procedures. Endod Top. 2005;10(1):3-29.

2. Peikoff MD, Trott JR. An endodontic failure caused by an unusual anatomical anomaly. J Endod. 1977;3(9):356-359.

3. Cleghorn BM, Christie WH, Dong CCS. Anomalous mandibular premolars: a mandibular first premolar with three roots and a mandibular second premolar with a C-shaped canal system. Int Endod J. 2008;41(11): $1005-1014$.

4. Cotton TP, Geisler TM, Holden DT, Schwartz SA, Schindler WG. Endodontic applications of cone-beam volumetric tomography. J Endod. 2007;33(9):1121-1132.

5. Ying Z, Yingtao D, Xiaoyan W, et al. Cone-beam computed tomography analysis of root canal configuration of 4674 mandibular anterior teeth. J Peking Univ Health Sci. 2014;46(1):95-99.

6. Qing-ping Z, Xing C. The relationship between the number of root canal $\&$ age in mandibular anterior teeth. Poster presented at: The 7th Annual Meeting of Chinese Geriatric Dentistry: Beijing, People's Republic of China; 2012:53-54.

7. You-nong W, Bao-li Y. Morphology research of 1976 permanent root canal. J Pract Stomatol. 1995;11(2):98-101.

8. Shu-fen S, Lin-xia L, Dan Z. Incidence of mandibular incisors with twice canals in Jilin province. Poster presented at: The 3rd Symposium of Chinese of Conservative Dentistry \& Endodontic Clinical Technique: Chongqing, People's Republic of China; 2009, 90.

9. Fleiss JL, Levin B, Paik MC. Statistical Methods for Rates and Proportions. 3rd ed. New York: John Wiley \& Sons; 2003.

10. Jing-you B. Preventive Dentistry. 5th ed. Beijing: People's Medical Publishing House; 2008.

11. Okamura T. Anatomy of the root canals. J Am Dent Assoc. 1927;14(4): 632-636.

12. Vertucci FJ. Root canal anatomy of the human permanent teeth. Oral Surg Oral Med Oral Pathol. 1984;58(5):589-599.

13. Pécora JD, Sousa Neto MD, Saquy PC. Internal anatomy, direction \& number of roots \& size of human mandibular canines. Braz Dent $J$. 1993;4(1):53-57.

14. Patel S, Dawood A, Ford TP, Whaites E. The potential applications of cone beam computed tomography in the management of endodontic problems. Int Endod J. 2007;40(10):818-830.

15. Bornstein MM, Wölner-Hanssen AB, Sendi P, von Arx T. Comparison of intraoral radiography \& limited cone beam computed tomography for the assessment of root-fractured permanent teeth. Dent Traumatol. 2009;25(6):571-577.

16. Mozzo P, Procacci C, Tacconi A, Martini PT, Andreis IA. A new volumetric CT machine for dental imaging based on the cone-beam technique: preliminary results. Eur Radiol. 1998;8(9):1558-1564.

17. Patel S, Horner K. 2009. The use of cone beam computed tomography in endodontics. Int Endod J. 2009;42(9):755-756.

18. Peters OA, Laib A, Rüegsegger P, Barbakow F. Three-dimensional analysis of root canal geometry by high-resolution computed tomography. J Dent Res. 2000;79(6):1405-1409.

19. Aminsobhani M, Sadegh M, Meraji N, Razmi H, Kharazifard MJ. Evaluation of the root and canal morphology of mandibular permanent anterior teeth in an Iranian population by cone-beam computed tomography. J Dent. 2013;10(4):358-366.

20. Vertucci FJ. Root canal anatomy of the mandibular anterior teeth. $J \mathrm{Am}$ Dent Assoc. 1974;89(2):369-371. 
21. Benjamin KA, Dowson J. Incidence of two root canals in human mandibular incisor teeth. Oral Surg Oral Med Oral Pathol. 1974;38(1): 122-126.

22. Kartal N, Yanıkoğlu FÇ. Root canal morphology of mandibular incisors. J Endod. 1992;18(11):562-564.

23. Calişkan MK, Pehlivan Y, Sepetçioğlu F, Türkün M, Tuncer SS. Root canal morphology of human permanent teeth in a Turkish population. J Endod. 1995;21(4):200-204.

24. Sikri VK, Sikri P. Root canal morphology of mandibular incisors. Endodontology. 1994;6(1):9-13.

25. Miyashita M, Kasahara E, Yasuda E, Yamamoto A, Sekizawa T. Root canal system of the mandibular incisor. J Endod. 1997;23(8):479-484.
26. Al-Qudah AA, Awawdeh LA. Root canal morphology of mandibular incisors in a Jordanian population. Int Endod J. 2006;39(11): 873-877.

27. Sert S, Aslanalp V, Tanalp J. Investigation of the root canal configurations of mandibular permanent teeth in the Turkish population. Int Endod J. 2004;37(7):494-499.

28. Milanezi de Almeida M, Bernardineli N, Ordinola-Zapata R. Microcomputed tomography analysis of the root canal anatomy and prevalence of oval canals in mandibular incisors. J Endod. 2013;39(12): 1529-1533.

\section{Publish your work in this journal}

Therapeutics and Clinical Risk Management is an international, peerreviewed journal of clinical therapeutics and risk management, focusing on concise rapid reporting of clinical studies in all therapeutic areas outcomes, safety, and programs for the effective, safe, and sustained use of medicines. This journal is indexed on PubMed Central, CAS,
EMBase, Scopus and the Elsevier Bibliographic databases. The manuscript management system is completely online and includes a very quick and fair peer-review system, which is all easy to use. Visit http://www.dovepress.com/testimonials.php to read real quotes from published authors.

Submit your manuscript here: http://www.dovepress.com/therapeutics-and-clinical-risk-management-journal 